\title{
Urban Rural Differences in Breast Cancer in New Zealand
}

\author{
Ross Lawrenson ${ }^{1, *}$, Chunhuan Lao ${ }^{1}$, Mark Elwood ${ }^{2}$, Charis Brown ${ }^{1}$, Diana Sarfati ${ }^{3}$ \\ and Ian Campbell ${ }^{4}$ \\ 1 National Institute of Demographic and Economic Analysis, The University of Waikato, \\ Hamilton 3240, New Zealand; clao@waikato.ac.nz (C.L.); charis@waikato.ac.nz (C.B.) \\ 2 School of Population Health, The University of Auckland, Auckland 1142, New Zealand; \\ mark.elwood@auckland.ac.nz \\ 3 Department of Public Health, The University of Otago, Wellington 6021, New Zealand; \\ diana.sarfati@otago.ac.nz \\ 4 School of Medicine, The University of Auckland, Auckland 1142, New Zealand; \\ Ian.campbell@waikatodhb.health.nz \\ * Correspondence: Ross.Lawrenson@waikatodhb.health.nz; Tel.: +64-7-839-8726 (ext. 97068) \\ Academic Editor: Peter Baade \\ Received: 19 August 2016; Accepted: 7 October 2016; Published: 11 October 2016
}

\begin{abstract}
Many rural communities have poor access to health services due to a combination of distance from specialist services and a relative shortage of general practitioners. Our aims were to compare the characteristics of urban and rural women with breast cancer in New Zealand, to assess breast cancer-specific and all-cause survival using the Kaplan-Meier method and Cox proportional hazards model, and to assess whether the impact of rurality is different for Māori and New Zealand (NZ) European women. We found that rural women tended to be older and were more likely to be Māori. Overall there were no differences between urban and rural women with regards their survival. Rural Māori tended to be older, more likely to be diagnosed with metastatic disease and less likely to be screen detected than urban Māori. Rural Māori women had inferior breast cancer-specific survival and all-cause survival at 10 years at $72.1 \%$ and $55.8 \%$ compared to $77.9 \%$ and $64.9 \%$ for urban Māori. The study shows that rather than being concerned that more needs to be done for rural women in general it is rural Māori women where we need to make extra efforts to ensure early stage at diagnosis and optimum treatment.
\end{abstract}

Keywords: rural; urban; breast cancer; Māori; equity; survival

\section{Introduction}

Many rural communities have poor access to health services due to a combination of distance from specialist services and a relative shortage of general practitioners. These disadvantages can lead to differences in health outcomes. Breast cancer is the most commonly diagnosed cancer in New Zealand (NZ) women with 3000 new cases each year. It is also an important cause of death with 617 deaths per year [1]. Urban rural differences in breast cancer are well known. A comprehensive systematic review of the international literature suggested rural women were 19\% more likely to be diagnosed with advanced stage at diagnosis [2]. Differences in mortality have also been shown between urban and rural women with breast cancer in Scotland [3], South Australia [4] and Germany [5]. It is difficult to generalise the findings from international studies as the definition of rurality can vary. For instance rural and remote communities in Australia and Canada will involve much greater distances from an urban medical centre than would be the case in Europe where population densities are greater. 
In New Zealand, differences have been shown in the presentation and outcomes of breast cancer for Māori and Pacific women compared with NZ Europeans [6,7]. A prior study using NZ cancer registry data did not show differences in breast cancer mortality or stage of diagnosis for urban versus rural women after adjustment for age, ethnicity and socioeconomic status [8]. However the NZ cancer registry data has missing data and limited information on other characteristics that may influence outcomes, and the missing data may be differential by urban/rural status. For example, it may be that those living in more rural areas are more likely to have data missing. There is also variation in the definition of what is considered a rural population. This study is based on substantially more detailed clinical data available (including accurate staging, screening history and presence of biological markers) from two clinical breast cancer registers in the Waikato and Auckland regions [9]. Waikato District Health Board has a large rural community with $60 \%$ of patients living outside the main centre of Hamilton, while Auckland on the other hand is mainly an urban community. Our aims were (1) to compare the differences and characteristics of rural women particularly stage of diagnosis and tumour size as these are important measures of differences in diagnosis; (2) to assess breast cancer-specific and all-cause survival for urban and rural women with breast cancer; and (3) to assess whether the impact of rurality is different for Māori and NZ European women in New Zealand.

\section{Methods}

The population for this study included all women diagnosed with invasive breast cancer in the Waikato and Auckland regions from June 2000 to May 2013. The two registers have been collecting data prospectively on newly diagnosed women with breast cancer and have accurate data on demographic characteristics including place of domicile as well as clinical data on the breast cancer at diagnosis and subsequent treatment. Ethical approval for this study was obtained from the New Zealand Northern "A" Health and Disability Ethics Committee (Ref. No. 12/NTA/42).

The definition of urban and rural varies considerably across different studies and countries. Within NZ a number of different definitions have been considered [10,11]. For this study we have taken the seven different classifications of the urban rural profile classification basis of NZ statistics which is based on both domicile and work place. The seven categories are Major Urban; Satellite Urban; Independent Urban; Rural with high urban influence; Rural with moderate urban influence; Rural with low urban influence and Highly Rural/Remote. We have categorised rural areas with high urban influence to be urban as these communities generally are the high socioeconomic population living close to urban centres where these families work, shop and receive health care. On the other hand the $\mathrm{NZ}$ independent urban centres are those independent towns where general practitioners are classified as being rural and receive a rural bonus. Consequently we have redefined urban as either a major or satellite urban community or communities of high urban influence. Rural we have considered to be independent urban communities or those designated rural with moderate or low or no urban influence.

Other variables included in the study were: age $(<40,40-49,50-59,60-69,70-79,80+$ years $)$, ethnicity (NZ European, Māori, Pacific, Asian, others), cancer stage (I, II, III, IV), grade (1, 2, 3), tumour size $(0-10,10-20,20-30,30-50,50+\mathrm{mm})$, mode of detection (screen detected, not screen detected), and hormone status (Estrogen receptor (ER) and progesterone receptor (PR) negative, ER and/or PR positive). We first compared the characteristics between urban and rural women, and then compared urban and rural Māori and NZ European women. Key demographic and disease characteristics were described for the total cohort, for urban and rural populations and stratified by ethnicity.

Mortality information including date of death and cause of death were from both the combined registers and the Mortality Collection in New Zealand. For all-cause survival analyses, patients without mortality information were considered to be censored on the last updated date for Mortality Collection which was 31 December 2014. For cancer-specific analyses, deaths from other causes were censored on the date of death. Cancer-specific and all-cause survival were assessed for rural and urban women at 5 and 10 years using Kaplan-Meier method. Models were fitted using Cox proportional hazards models 
with cancer-specific and all-cause deaths as outcomes of interests, to compare outcomes for rural compared with urban women for the whole cohort and stratified by ethnicity. The proportional hazards assumption was tested for both breast cancer-specific and total mortality by creating a time-dependent covariate as an interaction term between urban-rural residence and survival time. The survival difference between subgroups was considered significant if the $p$-value was less than 0.05 . All data analyses were performed in SPSS (IBM Corporation, New York, NY, USA).

\section{Results}

There were 12,372 women on the two registers with a diagnosis of invasive breast cancer. 2364 were classified as rural, living in an independent rural centre or a rural community, and 9885 were classified as urban (in 123 women domicile was not classified). When comparing the characteristics of urban and rural women with breast cancer, rural women tended to be older and were more likely to be Māori (Table 1). Stage of disease at diagnosis was similar and tumour size was also similar with $51.7 \%$ of rural women having a tumour size less than $20 \mathrm{~mm}$ and $50.3 \%$ of urban women $(p=0.238)$.

Table 1. Characteristics of urban and rural women.

\begin{tabular}{|c|c|c|c|c|c|c|c|}
\hline Characteristics & \multicolumn{2}{|c|}{ Rural } & \multicolumn{2}{|c|}{ Urban } & \multicolumn{2}{|c|}{ Total } & \multirow{2}{*}{$\frac{p \text {-Value (Chi-Square Test) }}{<0.001}$} \\
\hline \multicolumn{7}{|c|}{ Age Groups } & \\
\hline$<40$ & 126 & $5.3 \%$ & 669 & $6.8 \%$ & 795 & $6.5 \%$ & \\
\hline $40-49$ & 401 & $17.0 \%$ & 2263 & $22.9 \%$ & 2664 & $21.7 \%$ & \\
\hline $50-59$ & 626 & $26.5 \%$ & 2689 & $27.2 \%$ & 3315 & $27.1 \%$ & \\
\hline $60-69$ & 600 & $25.4 \%$ & 2233 & $22.6 \%$ & 2833 & $23.1 \%$ & \\
\hline $70-79$ & 364 & $15.4 \%$ & 1178 & $11.9 \%$ & 1542 & $12.6 \%$ & \\
\hline $80+$ & 247 & $10.4 \%$ & 853 & $8.6 \%$ & 1100 & $9.0 \%$ & \\
\hline \multicolumn{7}{|c|}{ Cancer Stage } & 0.066 \\
\hline I & 997 & $42.2 \%$ & 4291 & $43.4 \%$ & 5288 & $43.2 \%$ & \\
\hline II & 890 & $37.6 \%$ & 3643 & $36.9 \%$ & 4533 & $37.0 \%$ & \\
\hline III & 345 & $14.6 \%$ & 1514 & $15.3 \%$ & 1859 & $15.2 \%$ & \\
\hline IV & 132 & $5.6 \%$ & 437 & $4.4 \%$ & 569 & $4.6 \%$ & \\
\hline \multicolumn{7}{|c|}{ Grade } & $<0.001$ \\
\hline 1 & 557 & $25.3 \%$ & 2270 & $24.1 \%$ & 2827 & $24.4 \%$ & \\
\hline 2 & 1113 & $50.5 \%$ & 4281 & $45.5 \%$ & 5394 & $46.5 \%$ & \\
\hline 3 & 535 & $24.3 \%$ & 2850 & $30.3 \%$ & 3385 & $29.2 \%$ & \\
\hline Unknown & 159 & & 484 & & 643 & & \\
\hline \multicolumn{7}{|c|}{ Tumour Size $(\mathrm{mm})$} & 0.238 \\
\hline $0-20$ & 1123 & $51.7 \%$ & 4726 & $50.3 \%$ & 5849 & $50.5 \%$ & \\
\hline $20+$ & 1050 & $48.3 \%$ & 4674 & $49.7 \%$ & 5724 & $49.5 \%$ & \\
\hline Unknown & 191 & & 485 & & 676 & & \\
\hline \multicolumn{7}{|c|}{ Mode of Detection } & 0.909 \\
\hline Not screen detected & 1458 & $61.7 \%$ & 6084 & $61.5 \%$ & 7542 & $61.6 \%$ & \\
\hline Screen detected & 906 & $38.3 \%$ & 3801 & $38.5 \%$ & 4707 & $38.4 \%$ & \\
\hline \multicolumn{7}{|c|}{ ERPR } & 0.034 \\
\hline ER and PR negative & 395 & $17.1 \%$ & 1840 & $19.0 \%$ & 2235 & $18.7 \%$ & \\
\hline ER and/or PR positive & 1910 & $82.9 \%$ & 7819 & $81.0 \%$ & 9729 & $81.3 \%$ & \\
\hline Unknown & 59 & & 226 & & 285 & & \\
\hline \multicolumn{7}{|c|}{ Ethnicity } & $<0.001$ \\
\hline NZ European & 1932 & $82.2 \%$ & 6943 & $71.2 \%$ & 8875 & $73.3 \%$ & \\
\hline Māori & 311 & $13.2 \%$ & 844 & $8.7 \%$ & 1155 & $9.5 \%$ & \\
\hline Pacific & 38 & $1.6 \%$ & 759 & $7.8 \%$ & 797 & $6.6 \%$ & \\
\hline Asian & 47 & $2.0 \%$ & 920 & $9.4 \%$ & 967 & $8.0 \%$ & \\
\hline Others & 22 & $0.9 \%$ & 285 & $2.9 \%$ & 307 & $2.5 \%$ & \\
\hline Unknown & 14 & & 134 & & 148 & & \\
\hline Total & 2364 & $100 \%$ & 9885 & $100 \%$ & 12,249 & $100 \%$ & \\
\hline
\end{tabular}

ER: Estrogen receptor; RP: Progesterone receptor; NZ: New Zealand.

When we stratified by ethnicity, we find that rural Māori tended to be older, more likely to be diagnosed with metastatic breast cancer $(p<0.01)$ and less likely to be screen detected than urban Māori (Table 2). Rural NZ European were older and less likely to be diagnosed with Grade 3 cancer, 
but otherwise they had similar characteristics to urban NZ European including similar screen detected rates and similar stage at diagnosis.

Table 2. Urban and rural women Māori and NZ European.

\begin{tabular}{|c|c|c|c|c|c|c|c|c|c|c|c|c|}
\hline \multirow{2}{*}{ Characteristics } & \multicolumn{6}{|c|}{ Māori } & \multicolumn{6}{|c|}{ NZ European } \\
\hline & \multicolumn{2}{|c|}{ Rural } & \multicolumn{2}{|c|}{ Urban } & \multicolumn{2}{|c|}{ Total } & \multicolumn{2}{|c|}{ Rural } & \multicolumn{2}{|c|}{ Urban } & \multicolumn{2}{|c|}{ Total } \\
\hline \multicolumn{13}{|c|}{ Age Groups } \\
\hline \multicolumn{7}{|c|}{$p$-Value (Chi-Square Test) 0.043} & \multicolumn{6}{|c|}{$<0.001$} \\
\hline$<40$ & 23 & $7.4 \%$ & 74 & $8.8 \%$ & 97 & $8.4 \%$ & 95 & $4.9 \%$ & 407 & $5.9 \%$ & 502 & $5.7 \%$ \\
\hline $40-49$ & 66 & $21.2 \%$ & 238 & $28.2 \%$ & 304 & $26.3 \%$ & 303 & $15.7 \%$ & 1391 & $20.0 \%$ & 1694 & $19.1 \%$ \\
\hline $50-59$ & 100 & $32.2 \%$ & 264 & $31.3 \%$ & 364 & $31.5 \%$ & 488 & $25.3 \%$ & 1796 & $25.9 \%$ & 2284 & $25.7 \%$ \\
\hline $60-69$ & 82 & $26.4 \%$ & 183 & $21.7 \%$ & 265 & $22.9 \%$ & 491 & $25.4 \%$ & 1650 & $23.8 \%$ & 2141 & $24.1 \%$ \\
\hline $70-79$ & 29 & $9.3 \%$ & 72 & $8.5 \%$ & 101 & $8.7 \%$ & 324 & $16.8 \%$ & 926 & $13.3 \%$ & 1250 & $14.1 \%$ \\
\hline $80+$ & 11 & $3.5 \%$ & 13 & $1.5 \%$ & 24 & $2.1 \%$ & 231 & $12.0 \%$ & 773 & $11.1 \%$ & 1004 & $11.3 \%$ \\
\hline \multicolumn{13}{|c|}{ Cancer Stage } \\
\hline \multicolumn{7}{|c|}{$p$-Value (Chi-Square Test) 0.076} & \multicolumn{6}{|c|}{0.178} \\
\hline I & 112 & $36.0 \%$ & 315 & $37.3 \%$ & 427 & $37.0 \%$ & 837 & $43.3 \%$ & 3136 & $45.2 \%$ & 3973 & $44.8 \%$ \\
\hline II & 112 & $36.0 \%$ & 313 & $37.1 \%$ & 425 & $36.8 \%$ & 726 & $37.6 \%$ & 2546 & $36.7 \%$ & 3272 & $36.9 \%$ \\
\hline III & 53 & $17.0 \%$ & 162 & $19.2 \%$ & 215 & $18.6 \%$ & 279 & $14.4 \%$ & 1003 & $14.4 \%$ & 1282 & $14.4 \%$ \\
\hline IV & 34 & $10.9 \%$ & 54 & $6.4 \%$ & 88 & $7.6 \%$ & 90 & $4.7 \%$ & 258 & $3.7 \%$ & 348 & $3.9 \%$ \\
\hline \multirow{2}{*}{\multicolumn{7}{|c|}{$\begin{array}{c}\text { Grade } \\
p \text {-Value (Chi-Square Test) } 0.065\end{array}$}} & \multirow{2}{*}{\multicolumn{6}{|c|}{$<0.001$}} \\
\hline & & & & & & & & & & & & \\
\hline 1 & 56 & $19.7 \%$ & 181 & $22.5 \%$ & 237 & $21.7 \%$ & 469 & $26.0 \%$ & 1673 & $25.4 \%$ & 2142 & $25.5 \%$ \\
\hline 2 & 158 & $55.6 \%$ & 384 & $47.6 \%$ & 542 & $49.7 \%$ & 905 & $50.1 \%$ & 3009 & $45.6 \%$ & 3914 & $46.6 \%$ \\
\hline 3 & 70 & $24.6 \%$ & 241 & $29.9 \%$ & 311 & $28.5 \%$ & 432 & $23.9 \%$ & 1911 & $29.0 \%$ & 2343 & $27.9 \%$ \\
\hline Unknown & 27 & & 38 & & 65 & & 126 & & 350 & & 476 & \\
\hline \multicolumn{13}{|c|}{ Tumour Size $(\mathrm{mm})$} \\
\hline \multicolumn{7}{|c|}{$p$-Value (Chi-Square Test) 0.033} & \multicolumn{6}{|c|}{0.949} \\
\hline $0-20$ & 130 & $48.0 \%$ & 322 & $40.6 \%$ & 452 & $42.4 \%$ & 945 & $52.9 \%$ & 3497 & $52.9 \%$ & 4442 & $52.9 \%$ \\
\hline $20+$ & 141 & $52.0 \%$ & 472 & $59.4 \%$ & 613 & $57.6 \%$ & 843 & $47.1 \%$ & 3109 & $47.1 \%$ & 3952 & $47.1 \%$ \\
\hline Unknown & 40 & & 50 & & 90 & & 144 & & 337 & & 481 & \\
\hline \multirow{2}{*}{\multicolumn{7}{|c|}{$\begin{array}{c}\text { Mode of detection } \\
p \text {-Value (Chi-Square Test) } 0.323\end{array}$}} & \multirow{2}{*}{\multicolumn{6}{|c|}{0.960}} \\
\hline & & & & & & & & & & & & \\
\hline Not screen detected & 208 & $66.9 \%$ & 538 & $63.7 \%$ & 746 & $64.6 \%$ & 1170 & $60.6 \%$ & 4209 & $60.6 \%$ & 5379 & $60.6 \%$ \\
\hline Screen detected & 103 & $33.1 \%$ & 306 & $36.3 \%$ & 409 & $35.4 \%$ & 762 & $39.4 \%$ & 2734 & $39.4 \%$ & 3496 & $39.4 \%$ \\
\hline \multicolumn{13}{|c|}{ ERPR } \\
\hline \multicolumn{7}{|c|}{$p$-Value (Chi-Square Test) 0.389} & & & & & & \\
\hline ER and PR negative & 55 & $18.0 \%$ & 131 & $15.8 \%$ & 186 & $16.4 \%$ & 324 & $17.2 \%$ & 1275 & $18.8 \%$ & 1599 & $18.4 \%$ \\
\hline ER and/or PR positive & 251 & $82.0 \%$ & 696 & $84.2 \%$ & 947 & $83.6 \%$ & 1558 & $82.8 \%$ & 5518 & $81.2 \%$ & 7076 & $81.6 \%$ \\
\hline Unknown & 5 & & 17 & & 22 & & 50 & & 150 & & 200 & \\
\hline Total & 311 & $100 \%$ & 844 & $100 \%$ & 1155 & $100 \%$ & 1932 & $100 \%$ & 6943 & $100 \%$ & 8875 & $100 \%$ \\
\hline
\end{tabular}

When comparing 5-year and 10-year survival for urban versus rural women, we found that breast cancer survival is very similar for urban and rural women overall, but that for Māori women survival appears to be worse for rural compared with urban women (Table 3). Rural Māori women had inferior breast cancer-specific survival at 10 years at 72.1\% compared to 77.9\% for urban Māori $(p=0.072)$. The 5-year and 10-year all-cause survival was 71.6\% and 55.8\% for rural Māori women compared to $77.9 \%$ and $64.9 \%$ for urban Māori women ( $p=0.017)$.

The hazard ratios for mortality using the Cox proportional hazards model (Table 4) showed that rural NZ European women have similar breast cancer-specific mortality and all-cause mortality compared to urban NZ European women after adjustment for age, cancer stage, tumour size, grade, hormonal status (ERPR), year of diagnosis, mode of detection and comorbidity. However, survival was poorer for rural Māori women compared with urban Māori women for both cancer-specific and all-cause survival. The unadjusted hazard ratio for breast cancer-specific mortality and the all-cause mortality for rural Māori compared with urban Māori was 1.31 (95\% CI 0.97-1.76) and 1.33 (95\% CI 1.05-1.68), respectively. The hazard ratio increased to 1.47 (95\% CI 1.00-2.16) and 1.43 (95\% CI 1.08-1.91), respectively, after adjustment for other factors. The proportionality assumption was tested for each of the 6 models shown in Table 4, with no significant departure from proportionality shown in all models except that of all rural versus all urban women for total mortality, where there 
was significant evidence of interaction between urban-rural residence and survival time on the hazard ratio $(p=0.029)$.

Table 3. 5-year and 10-year breast cancer-specific survival and all-cause survival by Kaplan-Meier method.

\begin{tabular}{|c|c|c|c|c|c|}
\hline Groups & \multicolumn{2}{|c|}{5 -Year $(95 \%$ CI) } & \multicolumn{2}{|c|}{10 -Year $(95 \%$ CI) } & $\begin{array}{c}\text { Log Rank Test } \\
\text { ( } p \text {-Value })\end{array}$ \\
\hline \multicolumn{6}{|c|}{ Breast cancer-specific survival } \\
\hline Rural women & $86.6 \%$ & $(85.1 \%-88.1 \%)$ & $81.5 \%$ & $(79.6 \%-83.4 \%)$ & 0.211 \\
\hline Urban women & $88.0 \%$ & $(87.3 \%-88.7 \%)$ & $82.5 \%$ & $(81.5 \%-83.4 \%)$ & \\
\hline Rural Māori women & $78.3 \%$ & $(73.2 \%-83.5 \%)$ & $72.1 \%$ & $(65.8 \%-78.5 \%)$ & 0.072 \\
\hline Urban Māori women & $84.1 \%$ & $(81.4 \%-86.8 \%)$ & $77.9 \%$ & $(74.2 \%-81.5 \%)$ & \\
\hline Rural European women & $87.9 \%$ & $(86.3 \%-89.4 \%)$ & $82.7 \%$ & $(80.7 \%-84.8 \%)$ & 0.605 \\
\hline Urban European women & $88.6 \%$ & $(87.8 \%-89.4 \%)$ & $83.0 \%$ & $(81.9 \%-84.1 \%)$ & \\
\hline \multicolumn{6}{|c|}{ All-cause survival } \\
\hline Rural women & $80.6 \%$ & $(78.9 \%-82.3 \%)$ & $67.8 \%$ & $(65.4 \%-70.2 \%)$ & 0.007 \\
\hline Urban women & $82.7 \%$ & $(81.9 \%-83.4 \%)$ & $71.2 \%$ & $(70.1 \%-72.4 \%)$ & \\
\hline Rural Māori women & $71.6 \%$ & $(66.2 \%-77.0 \%)$ & $55.8 \%$ & $(48.2 \%-63.3 \%)$ & 0.017 \\
\hline Urban Māori women & $77.9 \%$ & $(74.9 \%-80.9 \%)$ & $64.9 \%$ & $(60.6 \%-69.2 \%)$ & \\
\hline Rural European women & $81.9 \%$ & $(80.0 \%-83.7 \%)$ & $69.0 \%$ & $(66.4 \%-71.6 \%)$ & 0.394 \\
\hline Urban European women & $82.0 \%$ & $(81.1 \%-83.0 \%)$ & $70.3 \%$ & $(69.0 \%-71.7 \%)$ & \\
\hline
\end{tabular}

Table 4. Hazard ratio for mortality estimated by Cox proportional hazards model.

\begin{tabular}{|c|c|c|c|c|}
\hline \multirow{2}{*}{$\begin{array}{l}\text { Groups } \\
\text { Breast cancer-specific mortality }\end{array}$} & \multicolumn{2}{|c|}{$\begin{array}{l}\text { Unadjusted Hazard } \\
\text { Ratio }(95 \% \text { CI })\end{array}$} & \multicolumn{2}{|c|}{$\begin{array}{c}\text { Adjusted Hazard }{ }^{1} \\
\text { Ratio }(95 \% \text { CI) }\end{array}$} \\
\hline & & & & \\
\hline Rural women compared with urban women & 1.08 & $(0.96-1.22)$ & 1.01 & $(0.87-1.17)$ \\
\hline Rural Māori women compared with urban Māori women & 1.31 & $(0.97-1.76)$ & 1.47 & $(1.00-2.16)$ \\
\hline Rural European women compared with urban European women & 1.04 & $(0.90-1.19)$ & 0.94 & $(0.79-1.10)$ \\
\hline \multicolumn{5}{|l|}{ All-cause mortality } \\
\hline Rural women compared with urban women & 1.13 & $(1.03-1.24) *$ & 1.04 & $(0.94-1.16)$ \\
\hline Rural Māori women compared with urban Māori women & 1.33 & $(1.05-1.68) *$ & 1.43 & $(1.08-1.91) *$ \\
\hline Rural European women compared with urban European women & 1.05 & $(0.94-1.16)$ & 0.90 & $(0.80-1.02)$ \\
\hline
\end{tabular}

${ }^{1}$ Adjusted for age, (ethnicity), cancer stage, tumour size, grade, hormonal status (ERPR), year of diagnosis, mode of detection and comorbidity. ${ }^{*} p$-Value $<0.05$.

\section{Discussion}

The key findings from this study is that there is no evidence that rural women in New Zealand are more likely to present with advanced stage of disease or have poorer outcomes. In our two regions it appears that rural women with breast cancer are older than urban women and that there are proportionately more rural Māori than urban Māori. The cancer-specific mortality rates for rural women were similar suggesting that access to breast cancer treatment is at least as good for rural women as urban.

However for Māori women with breast cancer outcomes are worse than for urban Māori. Rural Māori women do have lower rates of screen detected cancer and higher rates of metastatic disease. Overall there is a suggestion that both their breast cancer-specific mortality rate and all-cause mortality rate are not improved compared with urban Māori and may even be over $40 \%$ worse. One possible explanation for this is that deprivation may be more of an issue for Māori living in rural areas compared with non-Māori women which may have an additionally deleterious effect on survival. Similar observations have been reported from the USA. In one study socio-economic deprivation for native American Indians appeared to be more important than rurality [12] while in another study rural black American women were less likely to be screened and had more advanced disease at diagnosis [13]. Within New Zealand we know that there are health system barriers for Māori women with breast cancer. These include access to primary care and that when accessing specialist care lack of 
transport was a barrier-a key factor for rural women [14]. Access to primary care is important in that it has been shown that the more general practitioners per population, the earlier stage of diagnosis [15].

These findings are similar to those of our previous study using cancer registry data which showed no difference in stage or survival in rural women after adjustment for demographic factors. The screen detection rates in our rural women are re-assuring and suggest that our breast screening programs in Auckland and the Waikato are reaching rural women. The main concern is the overall lower rate in Māori women. These disparities are being addressed by Breast-screen Aoteoaroea. We have shown that rural Māori women can achieve high rates of breast screening if a concerted general practice based approach is taken to encouraging mammographic screening [16]. One of the factors that has been noted in Australia linked to poorer outcomes has been that rural women may be treated in a smaller centre by a low case load surgeon [17]. This is not a factor in our study as all women were treated in a high case load centre either in Auckland or Waikato. This may be one explanation for the lack of difference in overall outcomes.

The strengths of this study are that it is based on data from complete and high quality registers which have been collected prospectively. The weakness is that the study is dominated by the high number of urban women and relatively small numbers of rural Māori (311) which mean the results relating to Māori are less stable than the remainder of the results.

\section{Conclusions}

The study shows that, rather than being concerned that more needs to be done for rural women in general, it is rural Māori women where we need to make extra efforts to improve the later stage at diagnosis and ensure optimum treatment if we are to achieve equity in outcomes.

Acknowledgments: We acknowledge funding support received from the Health Research Council of New Zealand (Grant No. 14/484) for this study.

Author Contributions: Ross Lawrenson developed the concept and designed the study. Ross Lawrenson and Chunhuan Lao performed the data analyses. All authors contributed to the result interpretation and the final version of the manuscript. All authors read and approved the final manuscript.

Conflicts of Interest: The authors declare no conflict of interest.

\section{References}

1. Ministry of Health. Cancer: New Registrations and Deaths 2012; Ministry of Health: Wellington, New Zealand, 2015.

2. Nguyen-Pham, S.; Leung, J.; McLaughlin, D. Disparities in breast cancer stage at diagnosis in urban and rural adult women: A systematic review and meta-analysis. Ann. Epidemiol. 2014, 24, 228-235. [CrossRef] [PubMed]

3. Campbell, N.C.; Elliott, A.M.; Sharp, L.; Ritchie, L.D.; Cassidy, J.; Little, J. Rural factors and survival from cancer: Analysis of Scottish cancer registrations. Br. J. Cancer 2000, 82, 1863-1866. [CrossRef] [PubMed]

4. Wilkinson, D.; Cameron, K. Cancer and cancer risk in South Australia: What evidence for a rural-urban health differential? Aust. J. Rural Health 2004, 12, 61-66. [CrossRef] [PubMed]

5. Nennecke, A.; Geiss, K.; Hentschel, S.; Vettorazzi, E.; Jansen, L.; Eberle, A.; Holleczek, B.; Gondos, A.; Brenner, H.; GEKID Cancer Survival Working Group. Survival of cancer patients in urban and rural areas of Germany-A comparison. Cancer Epidemiol. 2014, 38, 259-265. [CrossRef] [PubMed]

6. Curtis, E.T.; Wright, C.; Wall, M. The epidemiology of breast cancer in Maori women in Aotearoa New Zealand: Implications for screening and treatment. N. Z. Med. J. 2005, 118, 1-10.

7. Seneviratne, S.; Campbell, I.; Scott, N.; Shirley, R.; Peni, T.; Lawrenson, R. Ethnic differences in breast cancer survival in New Zealand: Contributions of differences in screening, treatment, tumor biology, demographics and comorbidities. Cancer Causes Control. 2015, 26, 1813-1824. [CrossRef] [PubMed]

8. Bennett, H.; Marshall, R.; Campbell, I.; Lawrenson, R. Women with breast cancer in Aotearoa New Zealand: The effect of urban versus rural residence on stage at diagnosis and survival. N. Z. Med. J. 2007, 120, U2831. [PubMed] 
9. Seneviratne, S.; Lawrenson, R.; Harvey, V.; Ramsaroop, R.; Elwood, M.; Scott, N.; Sarfati, D.; Campbell, I. Stage of breast cancer at diagnosis in New Zealand: Impacts of socio-demographic factors, breast cancer screening and biology. BMC Cancer 2016, 16. [CrossRef] [PubMed]

10. Fearnley, D.; Lawrenson, R.; Nixon, G. "Poorly defined": Unknown unknowns in New Zealand rural health. N. Engl. J. Med. 2016, 129, 77-81.

11. Fraser, J. Rural Health: A Literature Review for the National Health Committee; Health Services Research Centre, School of Government, Victoria University of Wellington: Wellington, New Zealand, 2006.

12. Lin, Y.; Wimberly, M.C. Geographic Variations of Colorectal and Breast Cancer Late-Stage Diagnosis and the Effects of Neighborhood-Level Factors. J. Rural Health 2016. [CrossRef] [PubMed]

13. Williams, F.; Thompson, E. Disparity in Breast Cancer Late Stage at Diagnosis in Missouri: Does Rural Versus Urban Residence Matter? J. Racial Ethn. Health Dispar. 2016, 3, 233-239. [CrossRef] [PubMed]

14. Ellison-Loschmann, L.; Firestone, R.; Aquilina, L.; McKenzie, F.; Gray, M.; Jeffreys, M. Barriers to and delays in accessing breast cancer care among New Zealand women: Disparities by ethnicity. BMC Health Serv. Res. 2015. [CrossRef] [PubMed]

15. Ferrante, J.M.; Gonzalez, E.C.; Pal, N.; Roetzheim, R.G. Effects of Physician Supply on Early Detection of Breast Cancer. J. Am. Board Fam. Pract. 2000, 13, 408-414. [CrossRef] [PubMed]

16. Thomson, R.M.; Crengle, S.; Lawrenson, R. Improving participation in breast screening in a rural general practice with a predominately Maori population. N. Z. Med. J. 2009, 122, 39-47. [PubMed]

17. Roder, D.; Zorbas, H.; Kollias, J.; Pyke, C.; Walters, D.; Campbell, I.; Taylor, C.; Webster, F. Risk factors for poorer breast cancer outcomes in residents of remote areas of Australia. Asian Pac. J. Cancer Prev. 2013, 14, 547-552. [CrossRef] [PubMed]

(C) 2016 by the authors; licensee MDPI, Basel, Switzerland. This article is an open access article distributed under the terms and conditions of the Creative Commons Attribution (CC-BY) license (http://creativecommons.org/licenses/by/4.0/). 